\title{
La argumentación de profesores de Química en formación inicial (Práctica Profesional Docente II): un estudio de caso en Colombia
}

Autor: Pablo Antonio Archila Tipo de Tesis: Tesis doctoral

Directores: Dr. Carlos Javier Mosquera Suárez y Dr. Jean-Claude Regnier

Departamento: Departamento de Ciencias y Educación Universidades: Universidad Distrital Francisco José de Caldas - Université Lumière Lyon 2

Programa: Doctorado Interinstitucional en Educación, Universidad Distrital Francisco José de Caldas - Doctorado en Ciencias de la Educación, Université Lumière Lyon 2

Fecha de presentación: 20 de febrero del 2014

Fecha de recepción: julio $2014 \cdot$ Aceptado: julio 2014

Desde perspectivas habituales de la educación, se evidencia que la argumentación ha sido reducida a una técnica de la didáctica de las Ciencias cuando, en realidad, se trata de algo más complejo. Por tal razón, se hace necesario estudiar y comprender las formas de argumentación de los profesores de Química en formación inicial, pues son ellos quienes juegan un papel determinante en el fomento de la argumentación en los estudiantes. La premisa que se defiende en esta tesis es que un profesor de Quimica que aprende a argumentar enseña para que se aprenda argumentando, lo cual puede favorecer cambios relevantes en las prácticas escolares.

\section{OBJETIVOS ESPECÍFICOS}

1. Comprender las formas de argumentación utilizadas por tres profesores de Química en formación inicial (noveno semestre) de la Universidad Distrital Francisco José de Caldas evidenciadas durante sus prácticas profesionales docentes.

2. Identificar y caracterizar las formas de argumentación de tres profesores de Química en formación inicial.

3. Diseñar y aplicar una metodología de casos para el estudio de las formas de argumentación.

4. Proponer una fundamentación teórica y unos ejemplos de explicitación de contenidos argumentativos que puedan ser implementados en un currículo de formación inicial de profesores de Ciencias.

\section{REFERENTES TEÓRICOS}

Se consideran construcciones teóricas relevantes aquellas para cuya organización se disponen en cuatro perspectivas. La primera tiene que ver con los fundamentos de la argumentación en el campo del lenguaje; la segunda la constituyen los aportes de la argumentación como actividad lingüistica a la didáctica de 
las Ciencias; la tercera comprende los desarrollos de la argumentación en el campo de las Ciencias de la naturaleza y su enseñanza, y en la cuarta se trata una conceptualización acerca de la argumentación en la formación de profesores de Ciencias.

\section{TOMA Y TRATAMIENTO DE DATOS}

En esta investigación se realizó un estudio de tres casos. En su protocolo metodológico, se emplearon herramientas cuantitativas y cualitativas que comprendieron seis fases, a saber:

1. Diseño y aplicación de un cuestionario a 18 profesores de Química en formación inicial (noveno semestre), que fue validado por expertos de las Universidades Distrital Francisco José de Caldas y Lumière Lyon 2. Este instrumento permitió conocer algunas de las representaciones y prácticas de los profesores en formación inicial acerca del lugar de la argumentación en la enseńanza de la Química y sus relaciones con los trabajos prácticos de laboratorio (TPL) en el marco del espacio académico Práctica profesional docente II (PPDII).

2 y 4. Entrevista semiestructurada a cada uno de los tres casos antes y después del TPL con el fin de acceder a algunos de los propósitos e impresiones de los TPL diseñados y orientados por los tres sujetos, mediante sus verbalizaciones acerca de la planeación y expectativas relacionadas con los TPL y la argumentación.

3. Registro de vídeo de los TPL para identificar las formas de argumentación presentes en la interacción de cada uno de los tres profesores de Química en formación inicial con sus estudiantes durante los TPL.

5. Caracterización de la guía de TPL que cada caso diseñó para orientar a los estudiantes. Este ejercicio permitió conocer cómo estas herramientas didácticas favorecen -o no- el desarrollo de la argumentación de los estudiantes.

6. Construcción del módulo Enseñar química argumentando, para la formación en el tema de la argumentación de futuros profesores de Química.

\section{RESULTADOS Y CONCLUSIONES}

El estudio y la comprensión de las formas de argumentación de profesores de Química en formación inicial permite generar un conocimiento importante acerca de la argumentación, el cual sería de utilidad teórica y práctica para posteriores investigaciones que se desarrollen en el marco de la línea de investigación de formación de profesores así como para la mejora de los procesos enseñanza y el aprendizaje de la argumentación.

Los resultados brindan indicios de que los tres profesores de Química en formación inicial utilizan con sus estudiantes formas de argumentación que se producen luego de formular preguntas de tipo abierto. Sin embargo, estas formulaciones fueron escasas durante los TPL. Al respecto, los resultados confirman -en parte- a la formación inicial como un elemento que influye en las representaciones acerca del tema de la argumentación y, por ello, en las actividades y la importancia que los futuros profesores le dan a esta habilidad de pensamiento en las prácticas escolares. En tal sentido, la falta de preparación que afrontan de los profesores de Química en formación inicial acerca del tema de la argumentación genera limitaciones para que los futuros profesores involucren esta habilidad de pensamiento dentro de sus propósitos de enseñanza y aprendizaje.

De otra parte, los resultados de esta tesis constituyen los fundamentos del módulo Enseñar y aprender química argumentando, considerado como un objetivo secundario de la presente investigación, que es una propuesta para la mejora de la formación inicial de profesores de Ciencias. 